\title{
Association between radiological findings and severity of community-acquired pneumonia in children
}

\author{
Maria Francesca Patria ${ }^{1}$, Benedetta Longhi ${ }^{1}$, Mara Lelii ${ }^{1}$, Carlotta Galeone ${ }^{2}$, Maria Angela Pavesi ${ }^{3}$ \\ and Susanna Esposito ${ }^{1 *}$
}

\begin{abstract}
Background: There are few published data concerning radiological findings and their relationship with community-acquired pneumonia (CAP) severity. The aim if this study was to assess radiographic findings in children with CAP of different severity in order to evaluate whether some parameters are associated with severe CAP.

Methods: We analysed the characteristics of parenchymal densities in 335 chest radiographs of otherwise healthy children (173 males; mean age \pm standard deviation, $7.5 \pm 4.5$ years) admitted to our Emergency Room for CAP. Upon admission, chest radiographs were obtained in the two standard projections, and the children with severe or mild/moderate CAP were compared in order to identify any correlations between CAP severity and the radiological findings.

Results: Seventy-six of the 335 enrolled children (22.7\%) fulfilled the criteria for severe CAP. In comparison with the children with mild/moderate CAP, in severe CAP there was a significantly greater frequency of a bilateral multifocal distribution ( $p=0.01$ ), the simultaneous involvement of $\geq 3$ sites $(p=0.007)$, and the involvement of the right hilum $(p=0.02)$. The same results were confirmed in the multiple logistic regression model.

Conclusions: This study shows that radiological findings such as a multifocal bilateral distribution, the simultaneous involvement of at least three sites, and right hilar consolidation are associated with severe CAP in otherwise healthy children, and could be considered markers of disease severity in children with CAP.
\end{abstract}

Keywords: CAP, Chest radiograph, Community-acquired pneumonia, Pneumonia

\section{Background}

Community-acquired pneumonia (CAP) is a frequent childhood illness throughout the world, and a common reason for hospital admission [1,2]. The diagnosis of CAP in children is mainly based on clinical symptoms, and severe CAP is defined as the presence of fever, respiratory distress and/or dehydration [1,2]. There are differences between recently published guidelines in terms of the clinical criteria of severity, although all of the experts agree in considering hypoxemia the most important parameter for decision making [3-5]. Chest

\footnotetext{
* Correspondence: susanna.esposito@unimi.it

'Pediatric Clinic 1, Department of Pathophysiology and Transplantation, University of Milan, Fondazione IRCCS Ca' Granda Ospedale Maggiore Policlinico, 20122 Milan, Italy

Full list of author information is available at the end of the article
}

radiography is frequently performed in the Emergency Room even in mild to moderate cases, although appropriateness of performing chest radiography in children with CAP is still on debate and the actual guidelines recommend it only in order to verify the presence or absence of complications in patients with severe CAP [3-5]. There is evidence supporting the fact that radiographic findings did not correlate to any etiology [6], and chest radiography findings are not considered among the criteria for defining CAP severity. However, as there few published data concerning the relationship between the two, the aim of this study was to assess radiographic findings in children with CAP of different severity in order to evaluate whether some parameters are associated with severe CAP.

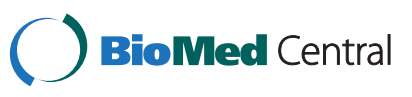




\section{Methods}

We analysed the characteristics of parenchymal densities in 335 chest radiographs of otherwise healthy children (173 males; mean age \pm standard deviation [SD], $7.5 \pm$ 4.5 years), who were enrolled by the Respiratory Disease Section of Pediatric Clinic 1, University of Milan, Milan, Italy, between January 2009 and December 2010 after being admitted to the Emergency Room because of CAP. Otherwise healthy children aged $<14$ years with clinical signs such as tachypnea and abnormal breath sounds, and a chest radiograph consistent with CAP were considered eligible for the study. All of the chest radiographs were evaluated by an independent expert radiologist (MAP) who was unaware of the patients' clinical and laboratory findings in accordance with the World Health Organisation $(\mathrm{WHO})$ criteria for the standardised interpretation of pediatric chest radiographs for a diagnosis of pneumonia [7]. Patients suffering from severe chronic underlying diseases, such as cystic fibrosis, bronchodysplasia, primary ciliary dyskinesia, swallowing dysfunction, immunodeficiency, congenital heart defects, neurological diseases or malformations were excluded. Other 149 children (70 males; mean age \pm SD, $2.1 \pm 3.3$ years) with a clinical diagnosis of CAP during the study period were not enrolled in the study because they were followed only in the Emergency Room and chest radiographies were not performed or were not available for evaluation in these patients. The study was approved by the Ethics Committee of Fondazione IRCCS Ca' Granda, Ospedale Maggiore Policlinico, Milan, Italy, and written informed consent was obtained from the parents or legal guardian of all of the enrolled children.

On the basis of the guidelines of the European Society for Pediatric Infectious Diseases [5], severe CAP was defined as the presence of one of the following findings: 1) respiratory distress defined on the basis of age-adjusted tachypnea, peripheral oxygen saturation $<93 \%$, cyanosis, retractions, grunting or nasal flaring; 2) a capillary refill time of $>2$ seconds or dehydration; and 3) vomiting/not feeding.

Upon admission, chest radiographs were obtained in the two standard projections. Eleven pulmonary fields were evaluated by the same blind expert radiologist (MAP): upper right lobe, upper left lobe, right middle lobe, lingula, right hilum, left hilum, right paracardiac, left paracardiac, retrocardiac, right lower lobe, left lower lobe. The presence of atelectasis, pleural effusion and interstitial lung disease was also considered. The distribution of abnormalities was categorised as focal when only one single pulmonary location was involved, and multifocal (unilateral or bilateral) when two or more areas were lesioned.

The children with severe or mild/moderate CAP were compared in order to identify any correlations between
CAP severity and the radiological findings. Categorical variables are given as numbers and percentages and were analysed using contingency table analysis with the chisquared or Fisher's test, as appropriate. The multivariate odds ratios (OR) of severe CAP, and the corresponding 95\% confidence intervals (CIs), were derived using unconditional multiple logistic regression models including terms for atelectasis and pleural effusion. All of the tests were two-sided and a p-value of less than 0.05 was considered statistically significant. The data were analysed using SAS version 9.1 (SAS Institute, Cary, NC, USA) statistical software.

\section{Results}

Seventy-six of the 335 enrolled children (22.7\%) fulfilled the criteria for severe CAP. They all had oxygen saturation of $<90 \%$ and other signs of respiratory distress, including age-adjusted tachypnea, cyanosis, retractions, grunting or nasal flaring; 39 (51.3\%) had difficulties in feeding; and 18 (23.7\%) were affected by vomiting. None of them had a capillary refill time of $>2$ seconds or dehydration.

The most frequent radiological presentation was focally distributed parenchymal densities (212, 63.3\%), whereas 123 patients (36.7\%) showed multifocal consolidations, predominantly bilaterally $(85 / 123,69.1 \%)$. Atelectasis and pleural effusions were detected in respectively 30 (8.9\%) and 33 patients $(9.8 \%)$, and only five radiographs (1.5\%) showed interstitial changes. Parenchymal densities were more prevalent in the right than the left lung (263 vs 179), and consolidations were more frequent in the middle lung than in the lower and upper areas (247 vs 176 and 19). The most frequently affected locations were the right lower lobe $(75,22.4 \%)$, the right paracardiac field $(65$, $19.4 \%)$, the left lower lobe $(63,18.8 \%)$, and the right hilum $(61,18.2 \%)$.

Table 1 summarises the associations between CAP severity and the radiological findings. In comparison with the children with mild/moderate CAP, there was a significantly greater frequency of a bilateral multifocal distribution $(\mathrm{p}=0.01)$, the simultaneous involvement of $\geq 3$ sites $(\mathrm{p}=0.007)$, and the involvement of the right hilum $(\mathrm{p}=0.02)$ in those with severe CAP. These findings were confirmed in the multiple logistic regression model, in which severe CAP associated with a bilateral multifocal distribution (OR 2.30; 95\% CI, 1.29-4.10), the simultaneous involvement of $\geq 3$ sites (OR 3.01; 95\% CI, 1.316.94), and involvement of the right hilum (OR 3.25; 95\% CI, 1.23-8.54). No association was found between CAP severity and the presence of atelectasis, middle right lobe involvement or pleural effusion.

\section{Discussion}

This study shows that a multifocal bilateral distribution, the simultaneous involvement of at least 3 sites, and right 
Table 1 Association between CAP severity and radiological findings

\begin{tabular}{|c|c|c|c|c|}
\hline Distribution (n) & Severe CAP (\%) & Mild to moderate CAP (\%) & $P$ value* & Adjusted $\mathrm{OR}^{\circ}(95 \% \mathrm{Cl})$ \\
\hline All locations $(n=335)$ & $n=76$ & $n=259$ & & \\
\hline Focal $(n=212)$ & $38(50.0)$ & $174(67.2)$ & & $1^{\S}$ \\
\hline Unilateral multifocal $(n=38)$ & $9(11.8)$ & $29(11.2)$ & \multirow[t]{3}{*}{0.01} & $1.25(0.53-2.97)$ \\
\hline Bilateral multifocal $(n=85)$ & $29(38.2)$ & $56(21.6)$ & & $2.30(1.29-4.10)$ \\
\hline Focal $(n=212)$ & $38(50.0)$ & $174(67.2)$ & & $1^{\S}$ \\
\hline 2 locations $(n=94)$ & $26(34.2)$ & $68(26.2)$ & \multirow[t]{2}{*}{0.007} & $1.68(0.93-3.04)$ \\
\hline$\geq 3$ locations $(n=29)$ & $12(15.8)$ & $17(6.6)$ & & $3.01(1.31-6.94)$ \\
\hline \multicolumn{5}{|l|}{ Pattern } \\
\hline Atelectasis: no $(\mathrm{n}=305)$ & $66(86.8)$ & $239(92.3)$ & \multirow{2}{*}{0.15} & $1^{\S}$ \\
\hline Atelectasis: yes $(n=30)$ & $10(13.2)$ & $20(7.7)$ & & $1.13(0.48-2.62)$ \\
\hline Pleural effusion: no $(n=302)$ & $68(89.5)$ & $234(90.3)$ & \multirow{2}{*}{0.82} & $1^{\S}$ \\
\hline Pleural effusion: yes $(n=33)$ & $8(10.5)$ & $25(9.7)$ & & $1.82(0.81-4.08)$ \\
\hline Only focal locations $(n=212)$ & $N=38$ & $N=174$ & & \\
\hline Right lower lobe: no ( $n=164)$ & $31(81.6)$ & $133(76.4)$ & \multirow{2}{*}{0.49} & $1^{\S}$ \\
\hline Right lower lobe: yes $(n=48)$ & $7(18.4)$ & $41(23.6)$ & & $0.55(0.24-1.28)$ \\
\hline Left lower lobe: no $(n=181)$ & $33(86.8)$ & $148(85.1)$ & \multirow{2}{*}{0.78} & $1^{\S}$ \\
\hline Left lower lobe: yes $(n=31)$ & $5(13.2)$ & $26(14.9)$ & & $0.92(0.33-2.58)$ \\
\hline Middle lobe: $n o(n=179)$ & $36(94.7)$ & $143(82.1)$ & \multirow{3}{*}{0.08} & $1^{\S}$ \\
\hline Middle lobe: yes $(n=33)$ & $2(5.3)$ & $31(17.8)$ & & $0.17(0.04-0.84)$ \\
\hline Right hilum: no $(n=190)$ & $30(78.9)$ & $160(92.0)$ & & $1^{\S}$ \\
\hline Right hilum: yes $(n=22)$ & $8(21.1)$ & $14(8.0)$ & \multirow[t]{2}{*}{0.02} & $3.25(1.23-8.54)$ \\
\hline Left hilum: no $(n=193)$ & $36(94.7)$ & $157(90.2)$ & & $1^{\S}$ \\
\hline Left hilum: yes $(n=19)$ & $2(5.3)$ & $17(9.8)$ & 0.38 & $0.50(0.11-2.26)$ \\
\hline Right paracardiac: no $(\mathrm{n}=176)$ & $30(78.9)$ & $146(83.9)$ & \multirow{3}{*}{0.46} & $1^{\S}$ \\
\hline Right paracardiac: yes $(n=36)$ & $8(21.1)$ & $28(16.1)$ & & $1.49(0.61-3.63)$ \\
\hline Other locations: no $(n=189)$ & $32(84.2)$ & $157(90.2)$ & & $1^{\S}$ \\
\hline Other locations: yes $(n=23)$ & $6(15.8)$ & $17(9.8)$ & 0.28 & $1.82(0.66-5.02)$ \\
\hline Upper lung: no $(n=209)$ & $38(100)$ & $171(98.3)$ & \multirow[t]{2}{*}{1.00} & $1^{\S}$ \\
\hline Upper lung: yes $(n=3)$ & 0 & $3(1.7)$ & & - \\
\hline Middle lung: no $(n=95)$ & $16(42.1)$ & $79(45.4)$ & \multirow[t]{2}{*}{0.71} & $1^{\S}$ \\
\hline Middle lung: yes $(n=117)$ & $22(57.9)$ & $95(54.6)$ & & $1.09(0.53-2.24)$ \\
\hline Lower lung: no $(n=120)$ & $22(57.9)$ & $98(56.3)$ & \multirow[t]{2}{*}{0.86} & $1^{\S}$ \\
\hline Lower lung: yes $(n=92)$ & $16(42.1)$ & $76(43.7)$ & & $1.01(0.49-2.08)$ \\
\hline
\end{tabular}

CAP: community-acquired pneumonia; Cl: confidence interval; OR: odds ratio.

*P values were calculated using two-sided chi-squared or Fisher's exact test, as appropriate.

${ }^{\circ}$ Estimates from multiple logistic regression models, including terms for atelectasis and pleural effusion (when appropriate).

§Reference category.

hilar consolidation are associated with severe CAP in otherwise healthy children.

Little has so far been published on the subject. Bay et al. studied eight children hospitalised because of severe avian influenza H5N1 pneumonia, and found that chest radiography may play an important prognostic role as the predominant radiological manifestations of the most complicated cases were multifocal bilateral consolidations, mainly located in the lower lobes [8]. A retrospective study of 210 children with viral pneumonia found that diffuse areas of air space consolidations were associated with acute respiratory distress syndrome and required mechanical ventilation [9]. No data are available on the association between severe bacterial CAP and radiographic findings, although there are studies showing that chest radiography did not identify any typical or atypical bacterial etiology regardless of CAP severity $[10,11]$. However, although multifocal bilateral involvement has been previously identified as 
a severity criteria, to the best of our knowledge this is first study showing a significant association between severity and right hilar involvement. Furthermore, although the atelectases were small or segmental and there were no massive pleural effusions or empyema, we did not find any correlation between CAP severity and the presence of either. In a previous report, Kin Ken et al. demonstrated that the frequency of upper lobe involvement was significantly higher among severe cases defined according to WHO but not British Thoracic Society criteria for patients aged $\geq 1$ year [12]. Although in our study the involvement of the upper areas occurred in a limited number of cases, we did not observe this type of association.

Ferrero et al. showed that upper lobe affection and pleural effusion were associated with pneumococcal isolation and with pneumococcal bacteremia, although no association with CAP severity has been performed in their study [13]. Michelow et al. observed that children with typical bacterial or mixed bacterial/viral infections had the greatest inflammation and disease severity, although none of the radiographic findings appeared associated with disease severity [14]. The limitations of our study include the lack of etiological data and other laboratory results as well as the fact that the information was only collected from otherwise healthy children with no serious underlying disease. Moreover, the mean age of our study population was quite high and patients were all enrolled among children admitted to hospital and followed by the Respiratory Disease Section of the Pediatric Clinic. This means that future research in this area is needed in order to identify possible correlations between the clinical criteria of severity, radiological characteristics, etiological findings and new laboratory biomarkers in order to develop a specific algorithm that can be easily used in clinical practice.

\section{Conclusions}

This study shows that radiological findings such as a multifocal bilateral distribution, the simultaneous involvement of at least three sites and right hilar consolidation are associated with severe CAP in otherwise healthy children, and could be considered markers of disease severity in children with CAP.

\footnotetext{
Abbreviations

CAP: Community-acquired pneumonia; Cl: Confidence interval; OR: Odds ratio; SD: Standard deviation.
}

\section{Competing interests}

The authors declare that they have no competing interests.

\section{Authors' contributions}

MFP drafted the manuscript and enrolled the patients; BL and ML participated in the enrolment of the CAP patients; CG made the statistical analysis; MAP performed and evaluated all the chest radiographs; SE coordinated and supervised the project, co-wrote the draft manuscript, and was head of the pediatric clinic at which the CAP patients were enrolled. All of the authors read and approved the final version of the manuscript.

\section{Acknowledgement}

This study was supported by a grant from the Italian Ministry of Health (Bando Giovani Ricercatori 2009).

\section{Author details}

${ }^{1}$ Pediatric Clinic 1, Department of Pathophysiology and Transplantation, University of Milan, Fondazione IRCCS Ca' Granda Ospedale Maggiore Policlinico, 20122 Milan, Italy. ${ }^{2}$ Luigi Devoto Department of Occupational Health, University of Milan, Milan, Italy. ${ }^{3}$ Pediatric Radiology Unit, Fondazione IRCCS Ca' Granda Ospedale Maggiore Policlinico, Milan, Italy.

Received: 22 July 2013 Accepted: 31 August 2013

Published: 13 September 2013

\section{References}

1. Nair H, Simões EA, Rudan I, Gessner BD, Azziz-Baumgartner E, Zhang JS, Feikin DR, Mackenzie GA, Moïsi JC, Roca A, Baggett HC, Zaman SM, Singleton RJ, Lucero MG, Chandran A, Gentile A, Cohen C, Krishnan A, Bhutta ZA, Arguedas A, Clara AW, Andrade AL, Ope M, Ruvinsky RO, Hortal M, McCracken JP, Madhi SA, Bruce N, Qazi SA, Morris SS, El Arifeen S, Weber MW, Scott JA, Brooks WA, Breiman RF, Campbell H, Severe Acute Lower Respiratory Infections Working Group, et al: Global and regional burden of hospital admissions for severe acute lower respiratory infections in young children in 2010: a systematic analysis. Lancet 2013, 381:1380-1390.

2. Liu L, Johnson HL, Cousens S, Perin J, Scott S, Lawn JE, Rudan I, Campbell H, Cibulskis R, Li M, Mathers C, Black RE, Child Health Epidemiology Reference Group of WHO and UNICEF: Global, regional, and national causes of child mortality: an updated systematic analysis for 2010 with time trends since 2000. Lancet 2012, 380:1308. 379:2151-2161. Erratum in: Lancet.

3. Harris M, Clark J, Coote N, Fletcher P, Harnden A, McKean M, Thomson A, British Thoracic Society Standards of Care Committee: British thoracic society guidelines for the management of community acquired pneumonia in children: update 2011. Thorax 2011, 66(Suppl 2):ii1-ii23.

4. Bradley JS, Byington CL, Shah SS, Alverson B, Carter ER, Harrison C, Kaplan SL, Mace SE, McCracken GH Jr, Moore MR, St Peter SD, Stockwell JA, Swanson JT: Executive summary: the management of communityacquired pneumonia in infants and children older than 3 months of age: clinical practice guidelines by the pediatric infectious diseases society and the infectious diseases society of America. Clin Infect Dis 2011, 53:617-630.

5. Esposito S, Cohen R, Domingo JD, Pecurariu OF, Greenberg D, Heininger U, Knuf M, Lutsar I, Principi N, Rodrigues F, Sharland M, Spoulou V, Syrogiannopoulos GA, Usonis V, Vergison A, Schaad UB: Antibiotic therapy for pediatric community-acquired pneumonia: do we know when, what and for how long to treat? Pediatr Infect Dis J 2012, 31:e78-e85.

6. Principi N, Esposito S: Management of severe community-acquired pneumonia of children in developing and developed countries. Thorax 2011, 66:815-822.

7. World Health Organization, Pneumonia Vaccine Trial Investigators' Group: Standardization of interpretation of chest radiographs for the diagnosis of pneumonia in children. Geneva: World Health Organization; 2001. WHON\&B/01.35.

8. Bay A, Etlik Ö, Öner F, Unal O, Arslan H, Bora A, Davran R, Yuca SA, Dogan M: Radiological and clinical course of pneumonia in patients with avian influenza H5N1. Eur J Radiol 2007, 61:245-250.

9. Guo W, Wang J, Sheng M, Zhou M, Fang L: Radiological findings in 210 paediatric patients with viral pneumonia: a retrospective case study. Br J Radiol 2012, 85:1385-1389.

10. Esposito S, Blasi F, Bellini F, Allegra L, Principi N, Mowgli Study Group: Mycoplasma pneumoniae and Chlamydia pneumoniae infections in children with pneumonia: Mowgli Study Group. Eur Respir J 2001, 17:241-245.

11. Esposito S, Marchese A, Tozzi AE, Rossi GA, Da Dalt L, Bona G, Pelucchi C, Schito GC, Principi N, Italian Pneumococcal CAP Group: Bacteremic pneumococcal community-acquired pneumonia in children less than 5 years of age in Italy. Pediatr Infect Dis J 2012, 31:705-710.

12. Kin Key N, Araújo-Neto CA, Nascimento-Carvalho CM: Severity of childhood community-acquired pneumonia and chest radiographic findings. Pediatr Pulmonol 2009, 44:249-252. 
13. Ferrero F, Nascimento-Carvalho CM, Cardoso MR, Camargos P, March MF, Berezin E, Ruvinsky R, Sant'Anna C, Feris-Iglesias J, Maggi R, Benguigui Y, CARIBE group: Radiographic findings among children hospitalized with severe community-acquired pneumonia. Pediatr Pulmonol 2010, 45:1009-1113.

14. Michelow IC, Olsen K, Lozano J, Rollins NK, Duffy LB, Ziegler T, Kauppila J, Leinonen M, McCracken GH Jr: Epidemiology and clinical characteristics of community-acquired pneumonia in hospitalized children. Pediatrics 2004, 113:701-707.

doi:10.1186/1824-7288-39-56

Cite this article as: Patria et al:: Association between radiological

findings and severity of community-acquired pneumonia in children.

Italian Journal of Pediatrics 2013 39:56.

\section{Submit your next manuscript to BioMed Central and take full advantage of:}

- Convenient online submission

- Thorough peer review

- No space constraints or color figure charges

- Immediate publication on acceptance

- Inclusion in PubMed, CAS, Scopus and Google Scholar

- Research which is freely available for redistribution 